\title{
Vertically aligned N-doped CNTs growth using Taguchi experimental design
}

Ricardo M. Silva ${ }^{1}$, António J.S. Fernandes ${ }^{2}$, Marta C. Ferro ${ }^{1}$, Nicola Pinna ${ }^{3}$, Rui F. Silva $^{1^{*}}$

1- CICECO, Department of Materials and Ceramic Engineering, University of Aveiro, 3810-193 Aveiro, Portugal.

2- I3N, Physics Department, University of Aveiro, 3810-193 Aveiro, Portugal.

3- Institut für Chemie, Humboldt-Universität zu Berlin, Brook-Taylor-Str. 2, 12489 Berlin Germany.

*Corresponding author: E-mail: rsilva@ua.pt (Rui F. Silva). Phone: +351-234370243 


\begin{abstract}
The Taguchi method with a parameter design $\mathrm{L}_{9}$ orthogonal array was implemented for optimizing the nitrogen incorporation in the structure of vertically aligned N-doped CNTs grown by thermal chemical deposition (TCVD). The maximization of the $\mathrm{I}_{\mathrm{D}} / \mathrm{I}_{\mathrm{G}}$ ratio of the Raman spectra was selected as the target value. As a result, the optimal deposition configuration was $\mathrm{NH}_{3}=90 \mathrm{sccm}$, growth temperature $=825^{\circ} \mathrm{C}$ and catalyst pretreatment time of $2 \mathrm{~min}$, the first parameter having the main effect on nitrogen incorporation. A confirmation experiment with these values was performed, ratifying the predicted $I_{D} / I_{G}$ ratio of 1.42 . Scanning electron microscopy (SEM) characterization revealed a uniform completely vertically aligned array of multiwalled CNTs which individually exhibit a bamboo-like structure, consisting of periodically curved graphitic layers, as depicted by high resolution transmission electron microscopy (HRTEM). The X-ray photoelectron spectroscopy (XPS) results indicated a 2.00 at.\% of $\mathrm{N}$ incorporation in the CNTs in pyridine-like and graphite-like, as the predominant species.
\end{abstract}

\title{
Keywords
}

Nitrogen doping, Carbon nanotubes, Chemical Vapor Deposition. 


\section{Introduction}

Energy storage systems represented by rechargeable batteries and supercapacitors are receiving increasing attention, as their applications are successively expanding from small-scale mobile electronics to large-scale transportations and utility grids [1-3]. Due to their unique combination of properties, carbon nanotubes (CNTs) are recognized materials in this field. As a matter of fact, the study of properties and applications of pristine CNTs has progressed enormously in the recent years and a great interest has been lately observed towards improving and controlling their properties through different functionalization methods. A modification of the crystalline nanotube properties by controllably placing defects or foreign atoms (heteroatoms) brings along tremendous technological applications [4]. Actually, the tuning of the CNT synthesis conditions can lead to significant variations in nanotube structure. One of the important possibilities of CNT modification is doping with nitrogen. Doping can dramatically change the electrical properties of the CNTs and the versatile thermal chemical vapor deposition (TCVD) technique has emerged as the most promising approach for mass production of CNTs. Namely, it has the ability to directly grow dense aligned CNTs, ranging within the $\mu \mathrm{m} / \mathrm{cm}$ scale length, not only of pure carbon structures but also of hetero-atoms doped structures, like nitrogen doped (N-doped) CNTs (N-CNTs) [5].

Nitrogen is considered one of the best dopants for carbon materials because the atomic radius of nitrogen is close to that of carbon. Nitrogen doping of CNTs creates an electron donor in the conduction band (n-type dopant), resulting in significant changes in internal structure, electrical conductivity and chemical reactivity. It is generally accepted that, the incorporation of nitrogen into a graphitic network can take place in one of two main ways: (i) graphitic-like and (ii) pyridine-like nitrogen. In graphitic-like incorporation, nitrogen bonds in same way as carbon, that is, with three bonds to other 
carbons. In the case of pyridine-like inclusion the nitrogen is bound to two carbon atoms [4]. When electrochemical surface reactions are present, like the oxygen reduction reaction (ORR) in fuel cells and supercapacitors, the different types of $\mathrm{N}$ species incorporated the carbon network are of noteworthy importance as much as the total nitrogen content [6-8]. The content of nitrogen in N-CNTs mainly depends on the solubility of the nitrogen in the catalyst nanoparticle at the temperature maintained during the synthesis and the concentration of the nitrogen-containing compound in the reaction mixture. These dissolved $\mathrm{N}$ atoms would precipitate with the $\mathrm{C}$ atoms during the growth of CNTs and this type of CNTs exhibit a bamboo-like structure in which the tube inside is separated into a series of compartments $[9,10]$.

Different kinds of nitrogen sources have used to dope CNTs, namely the using of nongaseous $\mathrm{N}$ precursor such as the injection of liquid organic chemical compounds rich in $\mathrm{N}$ have shown advantages in the growth of N-CNTs, specially by tailoring of number of walls of the N-CNTs ranging from single to multi walls [11-13]. In addition, Elías et al. demonstrated that the changes on the electrical properties of the grown single-walled $\mathrm{N}$ CNTs are related to the various concentrations of N liquid source in the feedstock [14]. Another way of adding nitrogen to the reaction environment is the incorporation of ammonia in gaseous form at room temperature, which can be simply added to the TCVD set up. The use of $\mathrm{NH}_{3}$ as $\mathrm{N}$ dopant produces mainly multi-walled N-CNTs. Doping levels achieved by this approach vary in the 0.4-9 at.\% range of $\mathrm{N}$, depending on the carbon gas source, catalyst precursor and deposition temperature [13]. Other nitrogen sources (e.g., melamine, pyridine, $\mathrm{N}_{2}$ ) can be used to grow N-CNTs, as also as more elaborated techniques (e.g., arc discharge, plasma or bias-assisted CVD), these leading to improved $\mathrm{N}$ incorporation levels (up to 30 at.\%) [13]. In short, it is possible 
to tune the $\mathrm{N}$ content and the number of walls of the $\mathrm{N}$ doped CNTs through the selection of the proper growth method and doping source.

Another important consequence of nitrogen incorporation in CNTs is the net increasing of defects on the CNT walls, changing the chemical behavior of a CNT. This procedure provides an alternative, less destructive, method to the classical oxidation methodology that typically uses nitric acid to functionalize the CNT surface. It is generally accepted that the N-modified CNTs will have more opportunities for practical applications [15]. Hence the N-CNTs are ideally suitable as support for a second material that can be deposited onto their surface, either as individual particles or as a film making them an ideal building block in heterostructured materials $[4,16]$.

The purpose of this work is to investigate the effects of the $\mathrm{N}$ doped CNTs growth parameters in a systematic manner through the Taguchi experimental design. Thermal CVD is a growth technique which involves a large number of tunable parameters, such as the carbon precursor and nitrogen doping source and catalyst, the type of carrier gas and its flow rate, and deposition temperature. The Taguchi methodology involves identification of controllable and uncontrollable parameters and the establishment of a series of experiments to determine their optimal combination, which has the greatest influence on the performance and least variation from the target design [17-22]. Specifically, in the present study the variables considered for the determination of the optimum level for each factor are: growth temperature, pretreatment time and ammonia flow rate. An $\mathrm{L}_{9}$ orthogonal array (9 experiments, 3 control factors and 3 levels) was created in the statistical design of experiments with the goal of maximization of the $\mathrm{N}$ incorporation in the structure. In this context, the $\mathrm{I}_{\mathrm{D}} / \mathrm{I}_{\mathrm{G}}$ ratio as determined by Raman studies was selected as output response of the deposition process. The ratio of the integrated areas of the $D$ and $G$ bands $\left(I_{D} / I_{G}\right)$ is often used to evaluate the degree of 
crystallinity in the CNTs. In this context, a lower value of the ratio indicates a less amount of defects in graphene-based structure of CNT materials [23]. Actually, the D band originates from the defects and would provide information on the level of disorder as a result of nitrogen doping. On the other hand, the $\mathrm{G}$ band results from the presence of defect-free crystalline graphitic carbon.

The morphology of the vertically aligned N-doped CNTs and the internal structure of the N-CNTs were investigated using scanning electron microscopy (SEM) and transmission electron microscopy (TEM). The content and type of nitrogen incorporation in the N-CNTs was estimated from X-ray photoelectron spectroscopy (XPS) measurements. The statistical software MINITAB 16 was used for the design of experiments (DoE) based on the Taguchi method.

\section{Experimental details}

\subsection{Catalyst preparation}

Polished Si (100) wafers with $200 \mathrm{~nm}$ thermally grown $\mathrm{SiO}_{2}$ were used as substrates. A preliminary set of experiments involving the use of different thickness of Fe films were carried out. The substrates were initially coated with a buffer layer of $10 \mathrm{~nm}$ thick $\mathrm{Al}_{2} \mathrm{O}_{3}$ and a catalyst film of 1, 2, 3 and $10 \mathrm{~nm}$ thick Fe by physical vapor deposition (RF and DC magnetron sputtering, respectively), followed by TCVD growth. More details of the $\mathrm{Al}_{2} \mathrm{O}_{3}$ and $\mathrm{Fe}$ film deposition were described in previous work [24]. This preliminary work enabled us to understand the catalyst thickness effect on the growth of the NCNTs by evaluating the correlation between the catalyst thickness and the length of the grown N-CNTs assessed by SEM. We observed that the N-CNTs preferentially grow on $10 \mathrm{~nm}$ thick Fe film with vertically alignment and uniformity. Therefore, the catalyst 
thickness of $10 \mathrm{~nm}$ was kept constant for experiments of the Taguchi experimental design.

\subsection{Synthesis of N-doped CNTs}

Nitrogen doped carbon nanotubes (N-CNTs) were grown by thermal CVD in a furnace reactor. The TCVD set-up consists of a horizontal mounted quartz tube (diameter $5 \mathrm{~cm}$ ) coupled to a thermal heating, equipped with various gas lines and standard mass flow controllers to control the flow of carbon source $\left(\mathrm{C}_{2} \mathrm{H}_{2}\right)$, reducing gas $\left(\mathrm{H}_{2}\right)$, doping gas $\left(\mathrm{NH}_{3}\right)$ and inert carrier gas (Ar) into the furnace and a PC station for automatic operation. The substrates coated with the catalytic layer were cut into $5 \times 5 \mathrm{~mm}$ and placed into the quartz tube of the furnace. The reactor was evacuated to $3.0 \times 10^{-3}$ mbar with a rotary pump. The quartz tube was subsequently filled with Ar up to atmospheric pressure. The substrate was pulled to the center of the reactor. Then, a two-step annealing process was initialized. The time of the first annealing step, in an Ar flow (750 sccm), was $5 \mathrm{~min}$. The time of the second annealing step, in a reductive flow of Ar (200 sccm) and $\mathrm{H}_{2}(500 \mathrm{sccm})$, was varied from 1 to $3 \mathrm{~min}$. The N-CNTs growth was undertaken with a total gas flow of $510 \mathrm{sccm}$ where the $\mathrm{C}_{2} \mathrm{H}_{2}$ flow was fixed at 10 sccm. The doping gas $\left(\mathrm{NH}_{3}\right)$ flow rate varied in the range of $30-90 \mathrm{sccm}$. The gas mixture was introduced for $15 \mathrm{~min}$ in the quartz tube where the temperature of the hot zone was set in the range of $825-875^{\circ} \mathrm{C}$. All these parameters were selected accordingly to preliminary set of experiments and literature data review $[5,9,10,23]$, that pointed out these conditions as suitable for the N-CNTs synthesis. 


\subsection{Sample characterization}

Scanning electron microscopy (SEM) was performed with a Hitachi SU-70 microscope operated in secondary electron mode at $15 \mathrm{kV}$. Transmission electron microscopy (TEM) measurements were carried out on a JEOL JEM-2200FS microscope operated at $200 \mathrm{kV}$. The sample for TEM measurements was prepared by dry adhesion of the NCNTs to a holey carbon grid from a N-CNTs forest. Raman spectroscopy (Jobin Yvon T64000) was carried out at a $532 \mathrm{~nm}$ excitation wavelength on the as-grown N-CNTs. The Raman spectra were taken at room temperature and two different locations are sampled. The values of $\mathrm{I}_{\mathrm{D}} / \mathrm{I}_{\mathrm{G}}$ ratio were estimated from integrated area intensities of the D and G band peaks. X-ray photoelectron spectroscopy (XPS) was conducted with a Kratos AXIS Ultra HAS. The analysis was carried out with a monochromatic Al K $\alpha$ Xray source $(1486.7 \mathrm{eV})$, operating at $90 \mathrm{~W}$, in FAT mode (Fixed Analyser Transmission), with a pass energy of $80 \mathrm{eV}$ for survey spectra and $40 \mathrm{eV}$ for high resolution energy spectra. The high resolution energy spectrum was used to determine the chemical environment and quantification of the elements present in the sample. Therefore, the $\mathrm{N}$ 1s spectrum was fitted to Gaussian functions. The N content, defined as atomic percentage of $\mathrm{N}$ with respect to the sum of $\mathrm{C}$ and $\mathrm{N}$ peaks, is estimated by the peak area ratio between $\mathrm{N}$ and $\mathrm{N}+\mathrm{C}$.

\subsection{Taguchi design of growth experiments}

In the N-CNTs synthesis process, three control factors (growth parameters) with three levels were experimented, leading to nine CVD experiments organized in a $\mathrm{L}_{9}$ Taguchi array design. The three growth parameters that were investigated were: i) growth temperature (values of 825,850 and $875^{\circ} \mathrm{C}$ ); ii) second annealing step hereinafter 
referred as pretreatment time (1, 2 and $3 \mathrm{~min})$; and iii) doping gas $\left(\mathrm{NH}_{3}\right)$ flow rate $(30$, 60 and $90 \mathrm{sccm}$ ). Subsequently, the $\mathrm{I}_{\mathrm{D}} / \mathrm{I}_{\mathrm{G}}$ ratio was selected as the physical quantity of interest to be the output response of the deposition process. The Taguchi method employs a generic signal-to-noise $(\mathrm{S} / \mathrm{N})$ ratio as quantitative measure for determining the optimum deposition conditions. There are primarily three categories of $\mathrm{S} / \mathrm{N}$ ratios, namely, the "smaller-is-better" type, the "larger-is-better" type, and the "nominal-isbest" type to choose from. The selection principles of $\mathrm{S} / \mathrm{N}$ ratio depend on the goal of the design. Hence, the maximization of the $\mathrm{N}$ incorporation in the nanotubes structure is the goal of this design, the "larger-is-better" approach was adopted, in which the S/N ratio is calculated from Equation 1:

$S / N_{\text {larger-is-better }}=-10 \log _{10}\left[\frac{1}{n} \sum_{i=1}^{n} \frac{1}{Y_{i}^{2}}\right]$

where $\mathrm{S} / \mathrm{N}$ indicates the signal to noise ratio statistic used in the Taguchi parameter analysis, $\mathrm{n}$ is the number of experiments, and $\mathrm{Y}_{\mathrm{i}}$ the $i$ th value of the output response used for the evaluation of the experiment $[16,17]$. Hence the variation analysis of $\mathrm{S} / \mathrm{N}$ ratios can be used to study the most significant factors affecting the N-CNTs growth via TCVD. The parameter design for N-CNTs growth process and the system response are exhibited in Table 1. The samples obtained under Taguchi array design are labeled as $\mathrm{R}_{n}$ with $n$ a number running from 1 to 9 . 


\section{Results and Discussion}

\subsection{Results of Taguchi-designed experiments}

In all experiments the N-CNTs have grown uniformly and normal to the substrate, normally assigned as vertically aligned N-CNTs or N-CNT forests, as shown in Figure 1 a.

The rightmost column of Table 1 reports the $\mathrm{N}-\mathrm{CNTs} \mathrm{I}_{\mathrm{D}} / \mathrm{I}_{\mathrm{G}}$ ratio as estimated from Raman studies. The results are illustrated in Figure $1 \mathrm{~b}$, which shows the Raman spectrum for each experiment of the Taguchi array. The main features in the Raman of CNTs are the so-called D and G bands, which lie at around $1340 \mathrm{~cm}^{-1}$ and $1580 \mathrm{~cm}^{-1}$ respectively.

The conditions used for experiment 3 (Figure 1b R3) appear to be the most promising in order to growth $\mathrm{N}-\mathrm{CNT}$ s forests, with an $\mathrm{I}_{\mathrm{D}} / \mathrm{I}_{\mathrm{G}}$ ratio of 1.48 (Table 1 ). In fact, varying the growth temperature, pretreatment time and $\mathrm{NH}_{3}$ flow produces changes in the $\mathrm{I}_{\mathrm{D}} / \mathrm{I}_{\mathrm{G}}$ ratio ranging from 0.93 to 1.48 . At lower $\mathrm{NH}_{3}$ flow rate (i.e. $30 \mathrm{sccm}$ ) the $\mathrm{I}_{\mathrm{D}} / \mathrm{I}_{\mathrm{G}}$ ratio attains the lowest ratio of 0.93 . On the other hand, at higher $\mathrm{NH}_{3}$ flow rate (i.e. 90 sccm), the value of the $I_{D} / I_{G}$ ratio is observed to be 1.48 . These results confirm the influence of the $\mathrm{N}$ content on the integrated area intensity ratio of $\mathrm{D}$ band to $\mathrm{G}$ band $\left(\mathrm{I}_{\mathrm{D}} / \mathrm{I}_{\mathrm{G}}\right)$. As a matter of fact, the N-doping of CNTs is known to degrade the crystallinity of graphitic layers [25].

\subsection{Response and variance analysis}

In order to assess in which extent each of the selected control factors is influential on the $I_{D} / I_{G}$ ratio and based on the results presented in Figure $1 b$, the corresponding $S / N$ 
response table and $\mathrm{S} / \mathrm{N}$ response graph were determined, according to Taguchi method, as shown in Table 2 and Figure 2, respectively.

The response table (Table 2) shows the average of each response characteristic $(\mathrm{S} / \mathrm{N}$ ratios) for each level of each factor. The tables include ranks based on the Delta statistic value, defined as the difference between the high and the low effect of each factor. The higher rank is assigned to the highest Delta value, which gives the highest contribution to the $I_{D} / I_{G}$ ratio intensity. In this context, the factor with the largest impact on the $S / N$ ratio is the $\mathrm{NH}_{3}$ flow rate and that with lowest impact is the pretreatment time, which is in agreement with the less pronounced variation of the $\mathrm{S} / \mathrm{N}$ ratio values.

In the response graphs of $S / N$ ratios in Figure 2, the $I_{D} / I_{G}$ ratio intensity increased by increasing the $\mathrm{NH}_{3}$ flow rate concomitantly with the concentration of the nitrogencontaining compound in the reaction mixture. Although the less pronounced variation of the $\mathrm{S} / \mathrm{N}$ ratio for larger-is-better analysis is due to the pretreatment time, this parameter plays an important role in the N-CNTs growth process. This is because during this step the catalyst film is subjected to a thermal treatment in a reducing gas environment $\left(\mathrm{H}_{2}\right)$ in order to remove surface oxides and it needs to be broken into nanosized islands for the nanotubes to grown on it. In fact, when N-CNTs growth starts, a vertical orientation emerges if there is enough density of the growing nanotubes to cause "crowding effect".

In addition to this, in order to understand the impact of various control factors on the response of experimental data, it is desirable to develop the ANOVA variance analysis and to find the significant factors in the Taguchi array. The ANOVA approach is applied to determine percentage contribution for each controlling factor, as shown in Table 3. In this table, the percentage of contribution of each factor on the response is given by $\%=S S / S S_{\text {total }} \times 100$ and the $S S$ is known as sum of squares. Furthermore, the 
F-value can also be used to determine which factor has a significant effect on the physical quantity of interest. Specially, when the F-value is large, it means that the change of a determined factor has a significant effect on the considered output. If the observed p-value is less than the significance level $(0.05)$ this indicates that the design parameters are statistically significant. It is observed from this table that the $\mathrm{NH}_{3}$ flow rate plays the most major contribution to the $\mathrm{I}_{\mathrm{D}} / \mathrm{I}_{\mathrm{G}}$ ratio, reaching as high as $63.31 \%$. Next, the growth temperature also gives a fairly large contribution of $26.72 \%$. On the other hand, the pretreatment time contribution of $5.61 \%$ seems to play a minor role on the $\mathrm{I}_{\mathrm{D}} / \mathrm{I}_{\mathrm{G}}$ ratio intensity. From a statistic table the critical $\mathrm{F}_{(3,11)}$ value can be determined as 3.98 for a level of significance equal to 0.05 . This critical $F$ value is lower compared to F-value obtained for each factor which means that all factors are significant for this purpose.

\subsection{Prediction and confirmation experiment}

The Taguchi method also allows the prediction of the output values that can be achieved by setting control-factors at the corresponding optimal configuration [21,26]. Based on the previous discussion, it is expected that the N-CNTs forest with highest $\mathrm{I}_{\mathrm{D}} / \mathrm{I}_{\mathrm{G}}$ ratio intensity is obtained at a temperature of $825^{\circ} \mathrm{C}, 2 \mathrm{~min}$ of pretreatment time and $90 \mathrm{sccm}$ flow rate of $\mathrm{NH}_{3}$. Therefore, the final step is to predict and verify the improvement of the quality characteristic using the optimal configuration of the design parameters. The expected value of $I_{D} / I_{G}$ ratio can be estimated by firstly calculating the predicted $S / N$ ratio. Its calculation was accomplished by using Minitab software, the resulting value being presented in Table 4 . 
By using the predicted $\mathrm{S} / \mathrm{N}$ value for $\mathrm{I}_{\mathrm{D}} / \mathrm{I}_{\mathrm{G}}$ ratio the corresponding estimated $\mathrm{I}_{\mathrm{D}} / \mathrm{I}_{\mathrm{G}}$ ratio can be calculated by written the Equation 1 as $3.02829=10 \log _{10} Y^{2}$. Finally, the predicted $\mathrm{Y}\left(\mathrm{I}_{\mathrm{D}} / \mathrm{I}_{\mathrm{G}}\right.$ ratio) value is 1.417 . In order to test this prediction one additional experiment is carried out. Figure 3a shows the Raman spectrum of the N-CNTs forest obtained from the optimal configuration. The observed $\mathrm{I}_{\mathrm{D}} / \mathrm{I}_{\mathrm{G}}$ ratio of 1.425 is in very good agreement with the predicted value. Consequently, the model provides valid predictions otherwise the above steps must be iterated.

Detailed surface morphological and structural investigations have been also carried out on the sample used in confirmation experiment. The inset of Figure $3 b$ shows the SEM image of the vertically well-aligned N-CNTs forest homogeneously grown on a large area of the substrate. The close up cross section image (Figure $3 b$ ) emphasizes the alignment of the N-CNTs that is an inherent feature of the growth process of forest depicting a relatively dense material. At this optimal configuration, the grown N-CNTs exhibit a length of $16 \mu \mathrm{m}$.

High resolution TEM images present more detailed information about the internal structure of N-CNTs. In Figure $3 \mathrm{c}$ it is seen that the N-CNTs exhibit the typical bamboo-like structure which consists of periodically curved graphitic layers. The crystallinity of the N-CNTs was examined by HRTEM together with Fast Fourier Transform (FFT). The ring-like pattern in FFT (inset) displayed in Figure 3c indicates the (002) and (004) planes of the graphite and the graphite walls still exhibit a good degree of crystallinity. The multi-walled nature of as-grown N-CNTs illustrated by the TEM studies is in good agreement with the Raman measurements. 
Among the analyzed growth parameters, we have found that the $\mathrm{NH}_{3}$ flow rate is the most important control factor in the $\mathrm{N}$ doping process, supported by the larger-is-better analysis of the $\mathrm{I}_{\mathrm{D}} / \mathrm{I}_{\mathrm{G}}$ ratio. In order to emphasize the importance of this parameter, the Raman spectra of N-CNTs synthesized with 90 and $30 \mathrm{sccm}$ of $\mathrm{NH}_{3}$ under the same growth temperature of $825^{\circ} \mathrm{C}$ and pretreatment time of 2 min, are compared in Figure 3d. Besides the strong $G$ and $D$ band characteristic of the first order Raman spectra of all graphitic materials, including multiwalled CNTs, there is another feature, the socalled 2D band located at $2700 \mathrm{~cm}^{-1}$, the most prominent second-order Raman peak whose frequency is approximately twice of the $\mathrm{D}$ band frequency. The origin of the $2 \mathrm{D}$ band is independent of the structural defects [25,27,28]. Comparing the Raman spectra in this plot, when the $\mathrm{NH}_{3}$ flow was reduced from 90 to $30 \mathrm{sccm}$, it was found that the $2 \mathrm{D}$ band increased its intensity and became narrower. So, if on one hand the 2D band is not related to the structural defects, on the other hand the $2 \mathrm{D}$ band is sensible to the $\mathrm{N}$ incorporation, which could be due to a modification in the electronic structure of nanotubes as a result of $\mathrm{N}$ doping [25,27].

This modification in the electronic structure of the N-CNTs may be directly related with the content and type of the incorporated $\mathrm{N}$. Therefore, the precise composition of the grown N-CNTs requires X-ray photoelectron spectroscopy (XPS) analysis which is a very powerful technique to study the nitrogen incorporation in the nanotube structure and its chemical environment. The XPS survey full scan spectrum of the obtained NCNTs from the confirmation experiment is shown in Figure 4a. The XPS measurements reveal the elemental composition of the sample where the main peaks are assigned to $\mathrm{C}$ $1 \mathrm{~s}, \mathrm{~N} 1 \mathrm{~s}$ edges of the $\mathrm{N}$-doped CNTs and $\mathrm{O} 1 \mathrm{~s}$ edge to corresponding to 285, 400 and $532 \mathrm{eV}$, respectively. The oxygen may arise from the oxygenated species created at the surface of the nanotubes once removed from the CVD chamber or in adsorbed form. A 
detail of the N 1s XPS spectrum of the N-CNTs is shown in Figure 4b. This spectrum presents at least three peaks corresponding to the different $\mathrm{N}$ chemical environment and these peaks can be assigned to the pyridine-like $\mathrm{N}$ where the $\mathrm{N}$ atom is bonded with two $\mathrm{C}$ atoms $(398.92 \mathrm{eV})$, graphite-like $\mathrm{N}$ where the $\mathrm{N}$ atom replaces a graphitic $\mathrm{C}$ atom $(401.72 \mathrm{eV})$ and to nitrogen oxide species $(404.98 \mathrm{eV})$. According to the literature [28,29] regarding N1s XPS spectrum, the same peaks were found when using $\mathrm{NH}_{3}$ as doping source. The total $\mathrm{N}$ content is determined to be 2.00 at. $\%$.

In order to emphasize the importance of the $\mathrm{NH}_{3}$ flow rate control factor, XPS analysis was conducted on N-CNTs grown under the same conditions with a lower content of $\mathrm{NH}_{3}$ e.g. $30 \mathrm{sccm}$ of $\mathrm{NH}_{3}$ and its XPS survey full scan and $\mathrm{N} 1 \mathrm{~s}$ spectrum is shown in Figures $4 \mathrm{c}$ and d, respectively. The N 1s XPS spectrum consists in one peak located at $401.79 \mathrm{eV}$ corresponding to the graphitic-like $\mathrm{N}$. At a flow rate of $30 \mathrm{sccm}$, the $\mathrm{N}$ content in the nanotubes was reduced to 0.25 at. $\%$.

According to the XPS results, the $\mathrm{N}$ in the nanotubes is chemically bonded with the $\mathrm{C}$ atoms of the graphitic network of the N-CNTs at a growth temperature of $825^{\circ} \mathrm{C}$. It can be seen that the graphitic-like $\mathrm{N}$ form is present in both samples. Furthermore, the $\mathrm{N}$ content decreased with decreasing the $\mathrm{NH}_{3}$ flow rate from 90 to $30 \mathrm{sccm}$. This trend of changing the $\mathrm{N}$ content with respect to the variation of the $\mathrm{N}$ source concentration in the reaction environment was also observed by Maldonado et al. where a linear relationship between the increase in the $\mathrm{N}$ content with increasing fraction of $\mathrm{NH}_{3}$ gas in the feedstock [30]. In addition, the $\mathrm{I}_{\mathrm{D}} / \mathrm{I}_{\mathrm{G}}$ ratio intensity also decreased from 1.42 to 1.00 (Figure 3d). Furthermore, the Raman spectroscopy was successfully used to follow the $\mathrm{N}$ incorporation into the graphitic network throughout the $\mathrm{I}_{\mathrm{D}} / \mathrm{I}_{\mathrm{G}}$ ratio. 
These results suggest that the content and type of the incorporated $\mathrm{N}$ induce the degradation of the crystallinity of graphitic layers which is consistent with the response graphs of $\mathrm{S} / \mathrm{N}$ ratio. Moreover, the SEM investigations revealed that the vertically alignment of the N-CNTs forests was achieved for the set of Taguchi designed CVD experiments. As such, the vertically aligned N-CNTs may find potential applications in developing various nanodevices, taking advantage of their large surface area and highly ordered geometry, especially in energy related fields of applications such as fuel cells and supercapacitors where the $\mathrm{N}$ content and species play a crucial role in their electrochemical performance.

\section{Conclusions}

The Taguchi method was successfully used for optimizing the growth conditions of vertically aligned $\mathrm{N}$-doped $\mathrm{CNTs}$ forests and to find the most suitable experimental conditions for the maximization of the $\mathrm{N}$ incorporation in the nanotube structure. Three design factors, namely the growth temperature, pretreatment time and $\mathrm{NH}_{3}$ flow rate, were selected as the variables at three levels each and an $\mathrm{L}_{9}$ orthogonal array was utilized for the design experiments.

Moreover, the Taguchi methodology allowed us to identify the most important factor on the N-CNTs growth, which affects the selected response. In this context, the ratio of D and $\mathrm{G}$ band integrated area ratio $\left(\mathrm{I}_{\mathrm{D}} / \mathrm{I}_{\mathrm{G}}\right)$ determined by Raman spectroscopy was selected as output response of the deposition process. The larger-is-better analysis of the $\mathrm{I}_{\mathrm{D}} / \mathrm{I}_{\mathrm{G}}$ ratio revealed that $\mathrm{NH}_{3}$ flow rate is the most important parameter and the ANOVA analysis provided the percentage contribution of each factor for results of the experiment in the following order: $\mathrm{NH}_{3}$ flow rate $>$ temperature $>$ pretreatment time. By 
optimal configuration of this method, N-CNTs were prepared and these results were in agreement with predicted data analyzed by the Taguchi method. Moreover, it is reasonable to propose that the described method can be adopted to rapidly adapt a literature-based TCVD process to the local laboratory reactor.

Transmission electron microscopy and Raman spectroscopy analysis of as-prepared NCNTs depicted multi walled nanotubes with the typical bamboo-like structure. The XPS analysis revealed that the atomic percentage of N-doped in CNTs can be controlled by varying the $\mathrm{NH}_{3}$ flow rate, attaining 2.00 at.\% $\mathrm{N}$ for $90 \mathrm{sccm}$. Also, it showed that nitrogen is chemically bonded with the $\mathrm{C}$ atoms of the graphitic network.

\section{Acknowledgements}

R.M. Silva is very grateful to FCT for the grant SFRH/BD/90844/2012. The X-ray photoelectron spectroscopy (XPS) analyses were done in the CEMUP at the University of Porto. The RNME - Pole University of Aveiro, FCT Project REDE/1509/RME/2005 is acknowledged. The authors would like to acknowledge Prof. Saveria Santagelo from University of Reggio Calabria for her critical reading of the manuscript and fruitful discussion. This work was developed in the scope of the project CICECO-Aveiro Institute of Materials (Ref. FCT UID /CTM /50011/2013), financed by national funds

through the FCT/MEC and co-financed by FEDER under the PT2020 Partnership Agreement. 


\section{References}

[1] W.H. Shin, H.M. Jeong, B.G. Kim, J.K. Kang, J.W. Choi, Nitrogen-Doped Carbon Nanotubes for Lithium Storage with Extremely High Capacity, Nano Lett. 12 (2012) 2283-2288.

[2] H. Zhang, G. Cao, Y. Yang, Carbon Nanotubes Arrays and their Composites for Electrochemical capacitors and Lithium-ion Batteries, Energy Environ. Sci. 2 (2009) 932-943.

[3] C. Du, J. Yeh, N. Pang, High Power Density Supercapacitors Using Locally Aligned Carbon Nanotubes Electrodes, Nanotechnology 16 (2005) 350-353.

[4] P. Ayala, R. Arenal, M. Rümmeli, A. Rubio, T. Pichler, The Doping of Carbon Nanotubes with Nitrogen and Their Potential Applications, Carbon 48 (2010) 575-586.

[5] Y.T. Lee, J. Park, Y.S. Choi, H. Ryu, H. J. Lee, Temperature-Dependent Growth of Vertically Aligned Nitrogen-Doped Carbon Nanotubes in the Range $800-1100^{\circ} \mathrm{C}$, J. Phys. Chem. B 106 (2002) 7614-7618.

[6] K.P. Gong, F. Du, Z. Xia, M. Durstock, L. Dai, Nitrogen-Doped Carbon Nanotubes Arrays with High Electrocatalytic Activity for Oxygen Reduction, Science 323 (2009) 760-764.

[7] D.S. Su, R. Schlogl, Nanostructured Carbon and Carbon Nanocomposites for Electrochemical Energy Storage Applications, ChemSusChem 3 (2010) 136-168.

[8] J.P. Paraknowitsch, A. Thomas, Doping Carbons Beyond Nitrogen: an Overview of Advanced Heteroatom Doped Carbons with Boron and Phosphorus for Energy Applications, Energy Environ. Sci. 6 (2013) 2839-2855.

[9] Y.T. Lee, N.S. Kim, S.Y. Bae, J. Park, S.C. Yu, H. Ryu, H. J. Lee, Growth of Vertically Aligned Nitrogen-Doped Carbon Nanotubes: Control of the Nitrogen Content over the Temperature Range 900-1100 C, J. Phys. Chem. B 107 (2003) 12958-12963.

[10] J.B. Kim, C.D. Kim, S.J. Kong, J.H. Kim, B.K. Min, W.S. Jung, H. R. Lee, Synthesize of N-Doped Carbon Nanotube According to Gas Flow Rate by Chemical Vapor Deposition, AIP Conf. Proc. 1399 (2011) 243-244.

[11] P. Ayala, A. Grüneis, T. Gemming, B. Büchner, M.H. Rümmeli, D. Grimm, J. Schumann, R. Kaltofen, F.L. Freire Jr., H.D. Fonseca Filho, T. Pichler, Influence of the Catalyst Hydrogen Pretreatment on the Growth of Vertically Aligned Nitrogen-Doped Carbon Nanotubes, Chem. Mater. 19 (2007) 6131-6137.

[12] P. Ayala, A. Grüneis, C. Kramberger, M.H. Rümmeli, I.G. Solórzano, F.L. Freire Jr., T. Pichler, Effects of the Reaction Atmosphere Composition on the Synthesis of Single and Multiwalled Nitrogen-Doped Nanotubes, The Journal of Chemical Physics 127 (2007) 1847091-1847096. 
[13] S. Boncel, S.W. Pattinson, V. Geiser, M.S.P. Shaffer, K.K.K. Koziol, En Route to Controlled Catalytic CVD Synthesis of Densely Packed and Vertically Aligned Nitrogen-Doped Carbon Nanotubes Arrays, Beilsten J. Nanotechnol. 5 (2014) 219-233.

[14] A.L. Elías, P. Ayala, A. Zamudio, M. Grobosch, E. Cruz-Silva, J.M. RomoHerrera, J. Campos-Delgado, H. Terrones, T. Pichler, M. Terrones, Spectroscopic Characterization of N-Doped Single-Walled Carbon Nanotube Strands: An X-ray Photoelectron Spectroscopy and Raman Study, J. Nanosci. Nanotechnol. 10 (2010) 3959-3964.

[15] D.H. Lee, W.J. Lee, S.O. Kim, Highly Efficient Vertical Growth of Wall-NumberSelected N-Doped Carbon Nanotube Arrays, Nano Lett. 4 (2009) 1427-1432.

[16] D. Eder, Carbon Nanotube-Inorganic Hybrids, Chem. Rev. 110 (2010) 1348-1385.

[17] P.J. Ross, Taguchi Techniques for Quality Engineering, 2nd edition, McGraw-Hill, 1996.

[18] A.C. Tamhane, Statistical Analysis of Designed Experiments, Theory and Applications; Wiley, 2009.

[19] J.H. Ting, C.C. Chang, S.L. Chen, D.S. Lu, C.Y. Kung, F.Y. Huang, Optimization of Field Emission Properties of Carbon Nanotubes by Taguchi Method, Thin Solid Films 496 (2006) 299-305.

[20] S. Porro, S. Musso, M. Giorcelli, A. Chiodoni, A. Tagliaferro, Optimization of a Thermal-CVD System for Carbon Nanotube Growth, Physica E 37 (2007) 16-20.

[21] S. Ebrahimiasl, W.Md.Z. Yunus, A. Kassim, Z. Zainal, Prediction of Grain Size, Thickness and Absorbance of Nanocrystalline Tin Oxide Thin Film by Taguchi Robust Design, Solid State Sciences 12 (2010) 1323-1327.

[22] S. Santagelo, M. Lanza, E. Piperopoulos, S. Galvagno, C. Milone, Optimization of CVD growth of CNT-based Hybrids Using the Taguchi Method, Materials Research Bulletin 47 (2012) 595-601.

[23] T. Sharifi, F. Nitze, H.R. Barzegar, C.W. Tai, M. Mazurkiewicz, A. Malolepszy, L. Stobinski, T. Wagberg, Nitrogen doped multi walled carbon nanotubes produced by CVD-correlating XPS and Raman spectroscopy for the study of nitrogen inclusion, Carbon 50 (2012) 3535-3541.

[24] D. Mata, R.M. Silva, A.J.S. Fernandes, , F.J. Oliveira, P.M.F.J. Costa, R.F. Silva, Upscaling Potencial of the CVD Stacking Growth Method to Produce DimensionallyControlled and Catalyst-Free Multiwalled Carbon Nanotubes, Carbon 50 (2012) 35853606. 
[25] L.G. Bulusheva, A.V. Okotrub, I.A. Kinloch, I.P. Asanov, A.G. Kurenya, A.G. Kudashov, X. Chen, H. Song, Effects of Nitrogen Doping on Raman Spectra of Multiwalled Carbon Nanotubes, phys. stat. sol. 245 (2008) 1971-1974.

[26] S.M. Kim, K.S. Park, K.D. Kim, S.D. Park, H.T. Kim, Optimization of Parameters for the Synthesis of Bimodal Ag Nanoparticles by Taguchi Method, J. Ind. Eng. Chem. 15 (2009) 894-897.

[27] M. S. Dresselhaus, A. Jorio, M. Hofmann, G. Dresselhaus, R. Satio, Perspectives on Carbon nanotubes and Graphene Raman Spectroscopy, Nano Lett. 10 (2010) 751758.

[28] J.C. Charlier, Defects in Carbon Nanotubes, Acc. Chem. Res. 35 (2002) 10631069 .

[29] J.W. Jang, C.E. Lee, S.C. Lyu, T.J. Lee, S.C. Lyu, T.J. Lee, Structural Study of Nitrogen-Doping Effects in Bamboo-Shaped Multiwalled Carbon Nanotubes, Appl. Phys. Lett. 84 (2004) 2877-2879.

[30] S. Maldonado, S. Morin, K.J. Stevenson, Structure, Composition and Chemical Reactivity of Carbon Nanotubes by Selective Nitrogen Doping, Carbon 44 (2006) 14291437. 


\section{List of Captions}

Figure 1. SEM cross-section images (a) and Raman spectra (b) of N-CNT forests grown from runs 1-9 of the Taguchi array in Table 1: R1, R2, R3, R4, R5, R6, R7, R8 and R9. The Raman spectra were normalized to the intensity of the $\mathrm{G}$ band.

Figure 2. Response graphs of $\mathrm{S} / \mathrm{N}$ ratio for larger-is-better analysis of $\mathrm{N}-\mathrm{CNTs} \mathrm{I}_{\mathrm{D}} / \mathrm{I}_{\mathrm{G}}$ ratio evaluation.

Figure 3. Raman spectrum (a), SEM (b) and HRTEM (c) images of the N-CNTs forest from the confirmation experiment. First and second-order Raman spectra (d) of N-doped multiwalled CNTs grown with 30 and $90 \mathrm{sccm}$ of $\mathrm{NH}_{3}$.

Figure 4. XPS spectra of N-CNTs grown with 90 and $30 \mathrm{sccm}$ of $\mathrm{NH}_{3}$. (a,c) full scan; (b,d) N 1s spectra, respectively.

Table 1. Parameter design and results of the growth experiments.

Table 2. Response table of $\mathrm{S} / \mathrm{N}$ ratios: larger-is-better.

Table 3. Analysis of variance (ANOVA computed using Minitab software).

Table 4. Optimal configuration and predicted $\mathrm{S} / \mathrm{N}$ ratio value. 
Figure 1

Click here to download Figure: Figure 1 final.docx

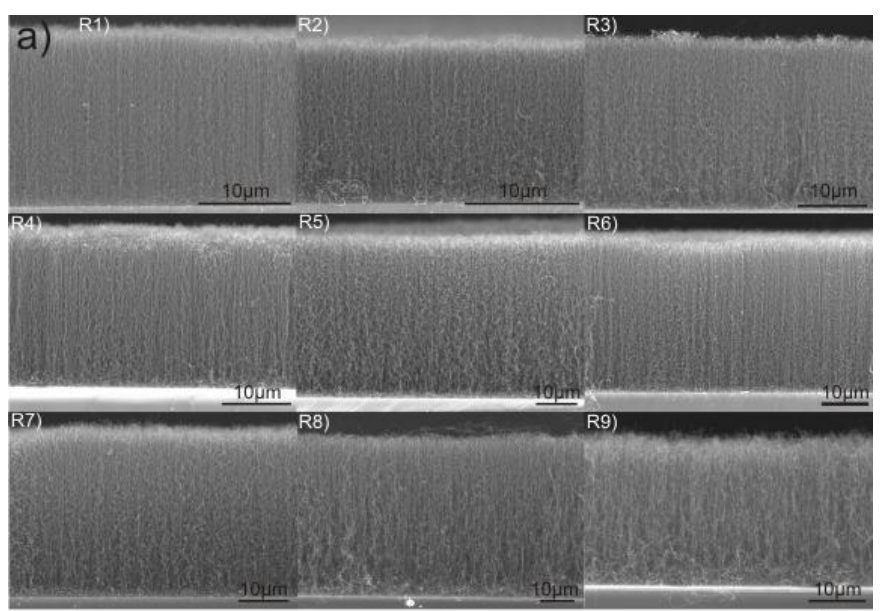

b)

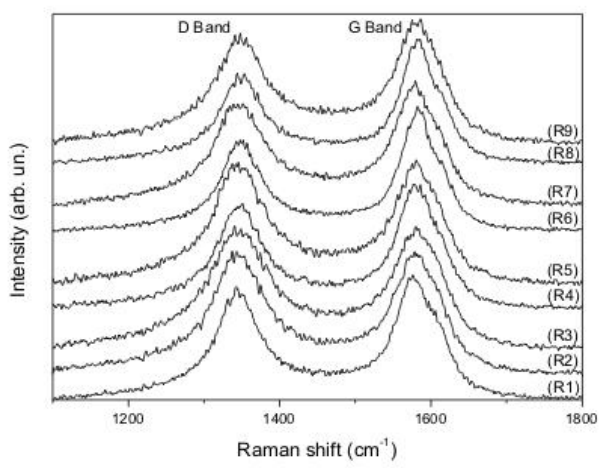

Figure 1 
Click here to download Figure: Figure 2 final.docx

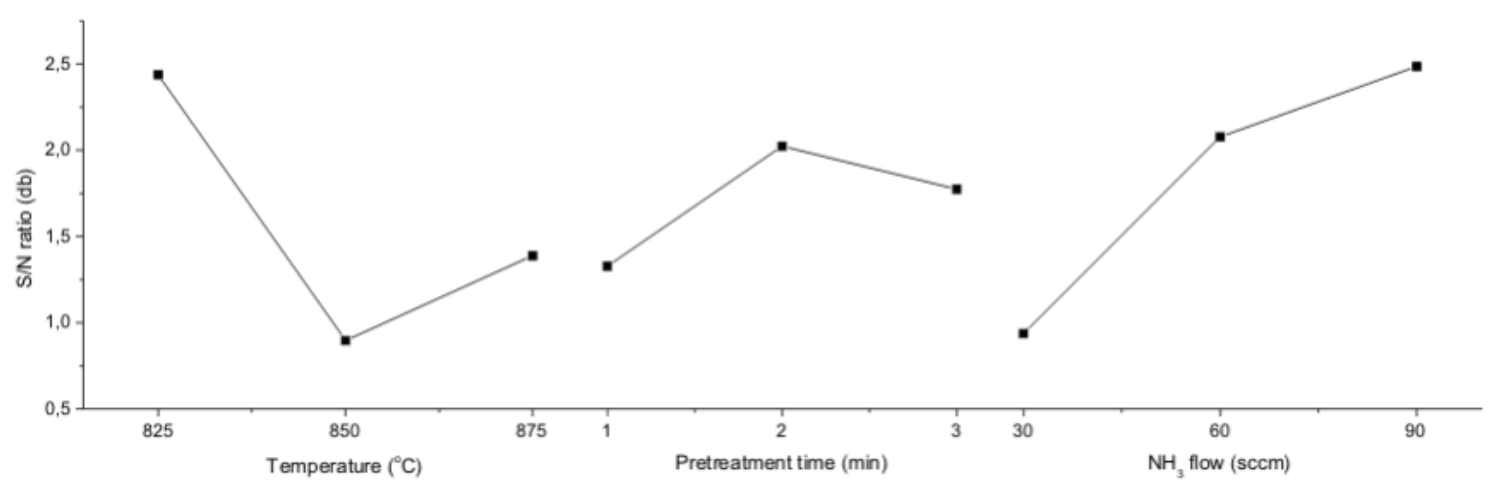

Figure 2 
Figure 3

Click here to download Figure: Figure 3 final.docx
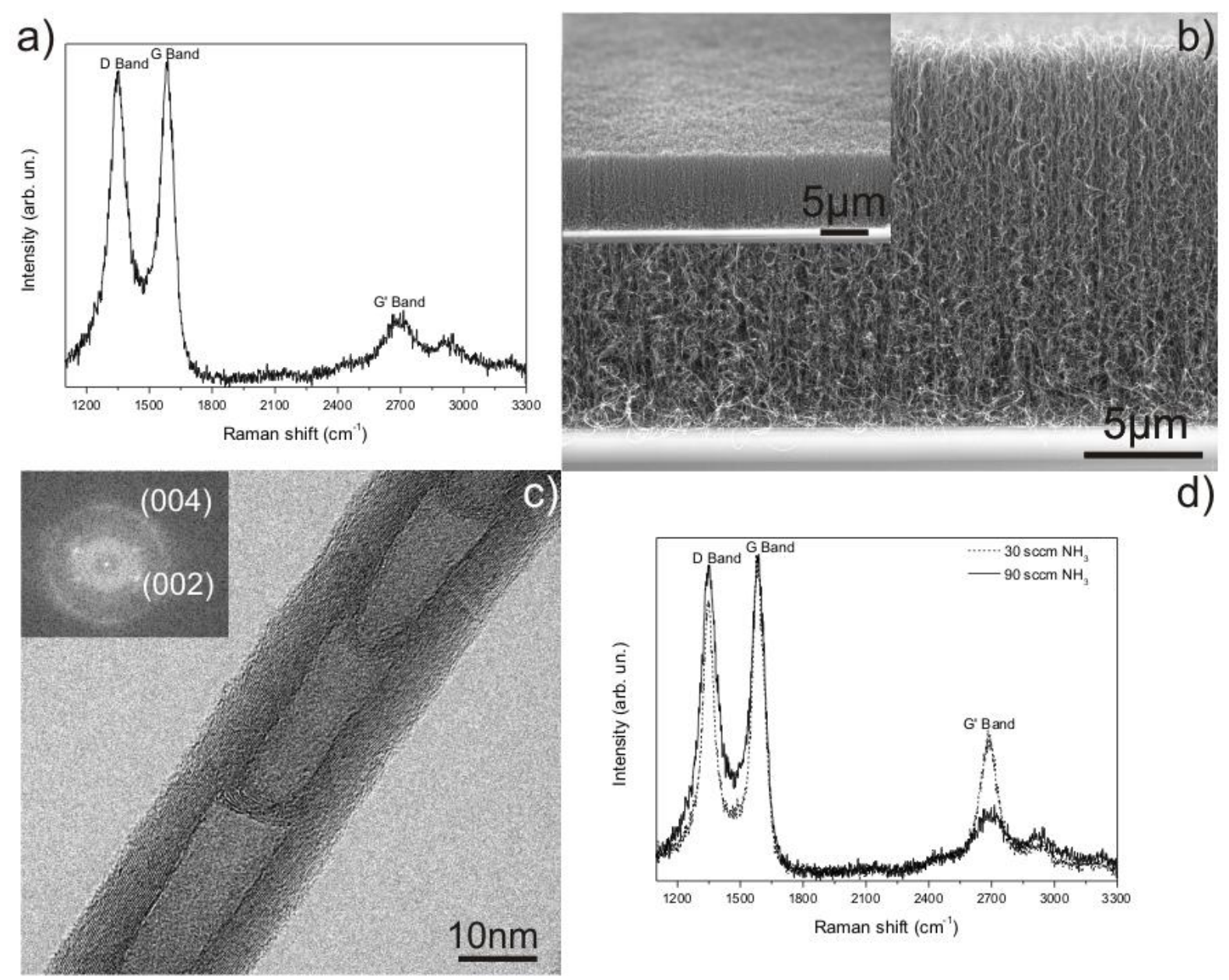

d)

Figure 3 
Figure 4

Click here to download Figure: Figure 4 final.docx

a)
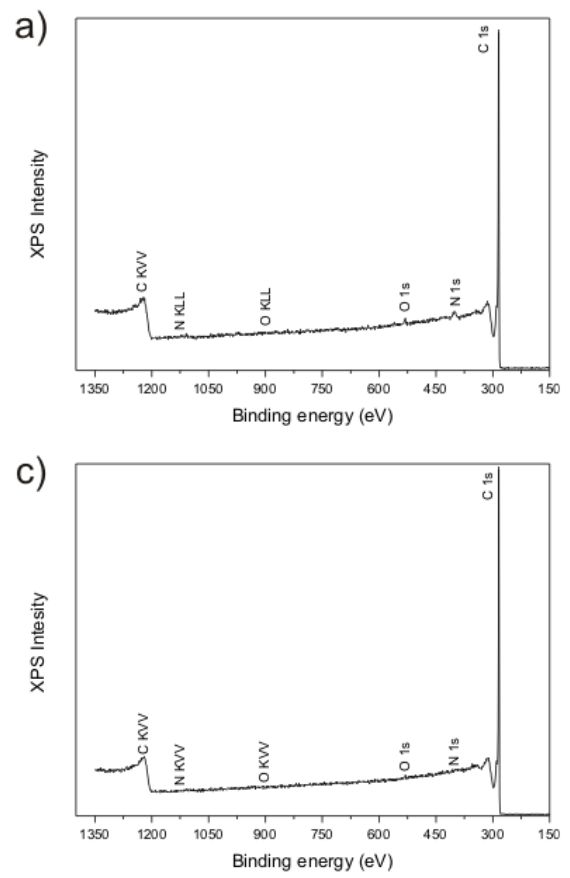

b)

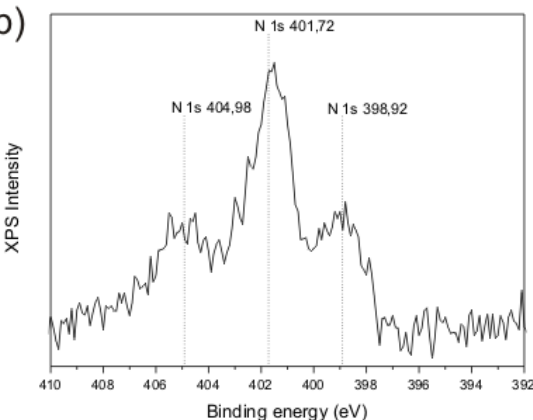

d)

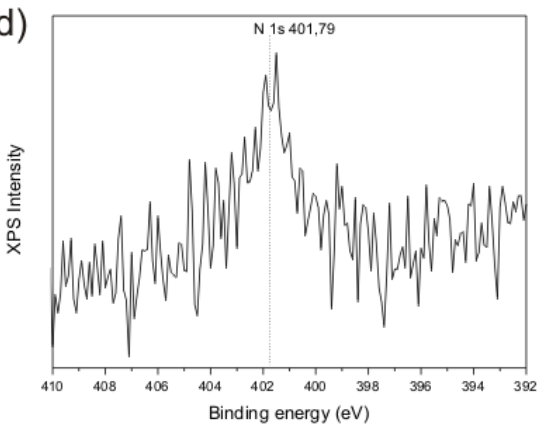

Figure 4 
Table 1

\begin{tabular}{|c|c|c|c|c|}
\hline$L_{9}$ & Factor $A$ & Factor $B$ & Factor $C$ & Response \\
\hline Run & $\begin{array}{c}\text { Temperature } \\
\left({ }^{\circ} \mathrm{C}\right)\end{array}$ & $\begin{array}{l}\text { Pretreatment } \\
\text { time (min) }\end{array}$ & $\begin{array}{c}\mathrm{NH}_{3} \text { flow } \\
\text { (sccm) }\end{array}$ & $\mathbf{I}_{D} / \mathbf{I}_{G}$ ratio \\
\hline R1 & 825 & 1 & 30 & 1.13 \\
\hline $\mathrm{R} 2$ & 825 & 2 & 60 & 1.39 \\
\hline R3 & 825 & 3 & 90 & 1.48 \\
\hline $\mathrm{R} 4$ & 850 & 1 & 60 & 1.11 \\
\hline R5 & 850 & 2 & 90 & 1.34 \\
\hline R6 & 850 & 3 & 30 & 0.93 \\
\hline R7 & 875 & 1 & 90 & 1.24 \\
\hline $\mathrm{R} 8$ & 875 & 2 & 30 & 1.02 \\
\hline R9 & 875 & 3 & 60 & 1.29 \\
\hline
\end{tabular}


Table 2

Table 2

\begin{tabular}{lccc}
\hline Level & $\begin{array}{c}\text { Temperature } \\
\left({ }^{\circ} \mathrm{C}\right)\end{array}$ & $\begin{array}{c}\text { Pretreatment } \\
\text { time (min) }\end{array}$ & $\begin{array}{c}\mathrm{NH}_{3} \text { flow } \\
(\mathbf{s c c m})\end{array}$ \\
\hline 1 & 2.4372 & 1.2361 & 0.1813 \\
2 & 0.8965 & 1.8544 & 1.9533 \\
3 & 1.3892 & 1.6324 & 2.5883 \\
Delta & 1.5407 & 0.6184 & 2.4070 \\
Rank & 2 & 3 & 1 \\
\hline
\end{tabular}


Table 3

\begin{tabular}{lcccccc}
\hline Source & $\begin{array}{c}\text { Degree of } \\
\text { freedom } \\
\text { (DF) }\end{array}$ & $\begin{array}{c}\text { Sum of } \\
\text { squares } \\
\text { (SS) }\end{array}$ & $\begin{array}{c}\text { Adjusted } \\
\text { mean } \\
\text { square } \\
\text { (Adj SS) }\end{array}$ & F-value & p-value & $\begin{array}{c}\text { Percentage } \\
\text { of } \\
\text { contribution } \\
(\%)\end{array}$ \\
\hline $\begin{array}{l}\text { Temperature } \\
\left({ }^{\circ} \mathrm{C}\right)\end{array}$ & 2 & 0.1434 & 0.0717 & 33.74 & 0.000 & 26.72 \\
$\begin{array}{l}\text { Pretreatment } \\
\text { time (min) }\end{array}$ & 2 & 0.0301 & 0.0150 & 7.08 & 0.011 & 5.61 \\
$\begin{array}{l}\mathrm{NH}_{3} \text { flow } \\
(\mathrm{sccm})\end{array}$ & 2 & 0.3397 & 0.1699 & 79.91 & 0.000 & 63.31 \\
$\begin{array}{l}\text { Error } \\
\text { Total }\end{array}$ & 11 & 0.0234 & 0.0021 & & & 4.36 \\
\hline
\end{tabular}


Table 4

Table 4

\begin{tabular}{cccc}
\hline $\begin{array}{c}\text { Temperature } \\
\left({ }^{\mathbf{0}} \mathbf{C}\right)\end{array}$ & $\begin{array}{c}\text { Pretreatment } \\
\text { time }(\mathbf{m i n})\end{array}$ & $\begin{array}{l}\mathbf{N H}_{3} \text { flow } \\
(\mathbf{s c c m})\end{array}$ & S/N ratio \\
\hline 825 & 2 & 90 & 3.02829
\end{tabular}

